\title{
Overcoming hierarchy in business model innovation: an actor-oriented approach
}

Overcoming hierarchy in business model innovation

Paolo Di Toma

Department of Communication and Economics, University of Modena and Reggio Emilia, Reggio Emilia, Italy, and Stefano Ghinoi Department of Economics and Management, University of Helsinki, Helsinki, Finland

Received 26 October 2019 Revised 24 February 2020 1 April 2020 14 May 2020 Accepted 17 May 2020

\begin{abstract}
Purpose - Business model innovation is a key element for firms' competitiveness. Its development can be supported by the establishment of an actor-oriented scheme to overcome hierarchical structures. The actororiented scheme is characterized by intra-organizational networks of relationships that can be established and dissolved between individuals. However, we lack an empirical perspective about its establishment; therefore, the purpose of this research is to advance our understanding of intra-organizational networks for supporting business model innovation.

Design/methodology/approach - Individuals create and manage knowledge aimed to innovate the business model through cognitive search and experiential learning mechanisms. Knowledge is spread within organizations by using intra-organizational advice networks, whose patterns reflect the presence of an actororiented scheme. This work applies social network analysis to network data from a multi-unit organization specializing in personal care services. We use a Logistic Regression-Quadratic Assignment Procedure to analyze intra-organizational network data on managers' advice exchange related to the learning modes of cognitive search and experiential learning.

Findings - Our research empirically identifies the main elements of an actor-oriented scheme in a business model innovation process. We find that managers are able to self-organize, because they are not influenced by their organizational roles, and that commons for sharing resources and protocols, processes and infrastructures enable advice exchange, thus showing the presence of an actor-oriented scheme in business model innovation process.
\end{abstract}

Research limitations/implications - This research is based on a cross-sectional database. A longitudinal study would provide a better understanding of the network evolution characterizing the innovation process. Practical implications - The results of our study support organizational decision-making for business model innovation.

Originality/value - This study provides empirical evidence of how an actor-oriented scheme emerges in a business model innovation process.

Keywords Business model innovation, Social network analysis, Actor-oriented scheme, Organizational learning

Paper type Research paper

\section{Introduction}

Firms are increasingly under pressure to improve their competitiveness in markets subject to rapid changes and uncertainty. Technological progress, demographic and lifestyle changes

(C) Paolo Di Toma and Stefano Ghinoi. Published by Emerald Group Publishing Limited. This article is published under the Creative Commons Attribution (CC BY 4.0) licence. Anyone may reproduce, distribute, translate and create derivative works of this article (for both commercial and non-commercial purposes), subject to full attribution to the original publication and authors. The full terms of this licence may be seen at http://creativecommons.org/licences/by/4.0/legalcode.

The Authors would like to thank the Editor and the anonymous Reviewers for their precious comments and suggestions.

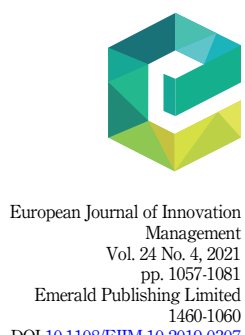

DOI 10.1108/EJIM-10-2019-0307 
EJIM

24,4

1058

require continuous adaptation to discontinuities arising in the business and social environment. Business models are sources of competitive advantage (Martins et al., 2015), hence "organizations are motivated to innovate business models by making fundamental changes in the way they create and appropriate value" (Berends et al., 2016, p. 182). In recent years, both scholars and practitioners have focused on business model innovation, by investigating its generative processes and its effects on firms' performance (Gatautis et al., 2019; Zott and Amit, 2010).

Organizational learning theories suggest that cognitive search (CS) and experiential learning (EL) are the main modes through which firms create and manage knowledge and ideas aimed to innovate the business model (Berends et al., 2016). These learning modes were first conceptualized by Gavetti and Levinthal (2000), which pointed out that organizational processes can be forward-looking, i.e. based on individuals' cognitive representations of strategy outcomes, or deriving from the experience acquired through trial and error learning activities. Afterwards, Berends et al. (2016) distinguished between four different mechanisms related to these learning modes: the conceptualization and the creation of business model components (which refer to the cognitive search mode), and the adaptation and the experimentation of these components (which refer to the experiential learning mode).

How is it possible to spread knowledge on the conceptualization, creation, adaptation and experimentation of an innovative business model within a firm? Aalbers and Dolfsma (2015) illustrate the importance of intra-organizational networks for developing innovation. Kelley et al. (2009, p. 222) describe networks "as avenues through which the diverse and situationspecific knowledge needs of an innovation project can be accessed across the organizational environment." Research has dedicated a growing interest in understanding formal and informal relationship patterns, interactions and perceptions between individuals in working groups that are effectively represented by social networks (Crawford and LePine, 2013; Park et al., 2020, p. 2). Social interactions between individuals allow the development of powerful coordination mechanisms that overcome the internal organizational boundaries (Kilduff and Krackhardt, 2008; Lomi et al., 2014). Business model innovation is resulting from the combination and recombination of knowledge derived from the cognitive search and experiential learning mechanisms, which can be facilitated by interpersonal information and advice sharing between individuals.

Among the lines of research addressing business model innovation, a prominent strand associates business model innovation to organizational change processes and focuses on organizational learning mechanisms (Achtenhagen et al., 2013; Andries and Debackere, 2013; Doz and Kosonen, 2010). However, significant theoretical gaps still remain with regard to the roles of cognition, learning and experimentation, and organizational design (Foss and Saebi, 2017, p. 213).

Informal intra-organizational networks coexist with the traditional hierarchical structure based on the mechanisms of control and coordination (Aalbers and Dolfsma, 2015; Pauget and Wald, 2018) but the increasing business complexity and the need for fast reaction to environmental challenges sometimes make hierarchy a less effective mechanism of control and coordination (Fjeldstad et al., 2012). Accordingly, scholars investigated organizational forms alternative to hierarchy (Lee and Edmondson, 2017), such as the actor-oriented scheme, which has been suggested as an organizational design effective to facilitate intraorganizational collaboration (Fjeldstad et al., 2012). However, we still lack a theoretical understanding of how these alternative organizational forms can be established and how they interact with the process of business model innovation.

In this paper, we fill this gap by investigating the establishment of an actor-oriented scheme within an organization developing business model innovation. Our empirical analysis focuses on the managers of a multi-unit leading cooperative firm specialized in personal care services, using social network analysis (SNA) for examining their intra-organizational 
networks of advice exchange related to the cognitive search and experiential learning mechanisms. SNA has been used to understand different organizational phenomena related to innovation management (e.g. Björk and Magnusson, 2009; Monaghan et al., 2017), and in recent years, several studies have applied this method to investigate intra-organizational networks (e.g. Aalbers and Dolfsma, 2015; Brennecke and Rank, 2017; Lomi et al., 2014). However, to the best of our knowledge, this is one of the first SNA studies exploring intraorganizational networks in the context of business model innovation. In this research, we apply a Logistic Regression-Quadratic Assignment Procedure (LR-QAP) to model the elements that influence managers' networking, in order to detect the establishment of an actor-oriented scheme.

This paper is structured as follows. We first discuss the theoretical framework on business model innovation and the actor-oriented organizational structure. Data and methodology are illustrated in the third section, which is followed by the presentation of the results. The fifth section is dedicated to the discussion of the results and the conclusions.

\section{Theoretical framework}

Over the last few years, research on business models and business model innovation has attracted significant attention but findings remain ambiguous and not conclusive. Different conceptualizations have been proposed, which often serve the scope of the particular phenomenon of interest to the researcher, but a lack of cumulative theory and empirical applications has so far slowed down the advancement of our understanding of the phenomenon (Foss and Saebi, 2017; Massa and Tucci, 2014; Zott et al., 2011). We refer to a business model as "the design or architecture of the value creation, delivery and capture mechanisms" of the firm (Teece, 2010, p. 172). This definition is consistent with the recent tendency of researchers to converge towards definitions of business model and business model innovation that focus on the architecture of the activities underlying the firm's creation, delivery and appropriation of value (Foss and Saebi, 2017; Massa and Tucci, 2014; Teece, 2010; Zott et al., 2011). Architecture represents the functional relationships between those mechanisms and the underlying activities. It also includes the need for organizations to be innovative and flexible, in order to reconfigure their know how in a novel way (Teece, 2018; Zott et al., 2011). According to Foss and Saebi (2017), the complementarity between activities underlying those mechanisms is the key element of the business model; therefore, business model innovation results from novel changes of such complementarities.

The nexus between business model and organizational design, as well as their reciprocal dynamic adaptation, has been recognized in management studies (Demil and Lecocq, 2009; Foss and Saebi, 2017; Zott and Amit, 2010). Previous research has mainly adopted a holistic and systemic view that includes a simultaneous consideration of both the content and the process of doing business, thus leading to a notion of business model that refers to an activity system (Teece, 2010; Zott and Amit, 2010). An innovation of the business model occurs when organizations change their structural key elements, re-shaping their internal procedures and creating new functional systems aligned with the external environment (Fjeldstad and Snow, 2018).

Nevertheless, business model innovation requires changes in the organizational design and a concerted effort of the management to span the internal boundaries in order to encourage collaborative thinking besides the hierarchical vertical structure of an organization (Mitchell and Coles, 2003).

Fjeldstad and Snow (2018) point out how the basic elements of the business model are connected to organizational processes, distinguishing between the operational and the dynamic dimension. The operational dimension involves the firm's basic choices regarding the selection of target customers, how the offering of products or services is shaped, and how
Overcoming hierarchy in business model innovation 
EJIM

24,4

1060 to produce and deliver the firm's offer to the market. According to Miles and Snow (1978), the firm designs an organizational form that should be best suited for controlling and coordinating the activities to carry out. The dynamic dimension addresses how a business model evolves over time and implies the organizational re-design so that the elements of the business model are constantly aligned to the environment in which the firm operates (Demil and Lecocq, 2009; Fjeldstad and Snow, 2018).

Berends et al. (2016) call attention to how organizational actors use different modes of organizational learning to manage business model components and define a coherent configuration to develop innovation. These modes are represented by cognitive search and experiential learning: in the former, action follows cognition, while in the latter cognition follows action. The business model's continuous adaptation processes rely upon the interaction and collaboration among the organizational actors or units (Eppler et al., 2011; Heikkilä et al., 2018; Saebi and Foss, 2015). Collaboration may drive value creation by boosting up the use of relevant knowledge and "unlock" cognitive search and experiential learning. In particular, the advice coming from other individuals is valuable for the definition of appropriate organizational strategies, conceptualizing and creating the new business model, as well as learning from the experience in order to adapt and experiment what has been modelled (Berends et al., 2016). Innovative organizations increasingly need to overcome traditional hierarchical model and seek to promote collaboration among individuals to strengthen their capacity to develop knowledge (Saebi and Foss, 2015; Pauget and Wald, 2018). Previous studies suggest that firms seeking to enhance the acquisition and internal re-elaboration of knowledge for developing business model innovation tend to reconfigure their organizational design, practices and capabilities (e.g. Sosna et al., 2010). Organizational perspectives address business models as devices for structuring and designing organizations (Foss and Saebi, 2017) and emphasize the relevance of experimentation and learning (Eppler et al., 2011; Sosna et al., 2010). Even though traditional organizational forms employ hierarchical mechanisms for pursuing control and coordination, less "hierarchical" organizational forms have been observed in complex and dynamic contexts (Fjeldstad et al., 2012). The organizational design defines control and coordination activities pursued by structures and processes resulting from the separation and integration of resources. Organizational structures and processes are designed and reconfigured to deal with emerging needs, according to environmental changes over time. Integration corresponds to the quality of collaboration between organizational units that are required to produce results in a coordinated manner (Miles and Snow, 1978), and it is obtained through a range of mechanisms for reciprocal adjustment.

The process of business model innovation also depends on the firm's organizational culture that refers to the organizational values communicated through norms, artifacts and can be observed in behavioral patterns (Hock et al., 2016; Homburg and Pfesser, 2000; Schein, 1992). Values act as social principles that inspire the behavior of the members of the organization and create a general framework that provides guidance in implementing organizational routines and practices (Hatch, 1993; O'Reilly et al., 1991). As it shapes patterns of behavior and affects the way members of an organization interact with each other (Shin et al., 2012), the organizational culture acts as a cognitive barrier, or as an enabler of business model innovation (Hogan and Coote, 2014). An organization's culture strongly influences employees' behavior beyond formal control mechanisms, procedures and authority (O'Reilly et al., 1991) and is a key factor to fostering processes that support innovation (Khazanchi et al., 2007; Tellis et al., 2009). Therefore, the acquisition of a full understanding of the activity system that represents the current business model and the basis for its change and innovation (Zott and Amit, 2010) should consider the underlying cognitive fundamentals and the logic that drives these activities (Hock et al., 2016, p.434).

The organizational culture is strongly linked to the dynamics of change and innovation of the business model. Previous research highlighted the crucial role of culture in ensuring 
employee involvement during the process of business model change (Shin et al., 2012; Achtenhagen et al., 2013), the link between employees' attitude and organizational effectiveness (Gregory et al., 2009), the positive impact of creative culture on strategic flexibility (Bock et al., 2012), the strong influence of shared organizational cognitions on the strategic choices of managers during organizational change (Aspara et al., 2013) and the meaningful contribution to knowledge management and organizational effectiveness (Zheng et al., 2010).

The need for organizations to provide appropriate and timely responses is a challenge for the effectiveness of traditional hierarchical forms to promote and enhance collaboration between the organizational actors. The shortcomings of the hierarchical forms depend on the barriers that interpose to the direct interaction and the following delays that affect the collaboration between organizational actors or units (Fjeldstad et al., 2012). Firms dealing with multiple dimensions of geography, market segments, channels, products or services need to develop an organizational capacity of multidimensional coordination (Galbraith, 1974). In some cases, firms adopt open innovation or co-development partnerships to gain access to resources that overcome the constraints of their own borders or internal coordination models, while strengthening their capacity to innovate their business model (Appleyard and Chesbrough, 2017; Saebi and Foss, 2015). Hence, new organizational designs emerge, trying to experiment more open, fast and (eventually) temporary collaborations between individuals or organizational units. Fjeldstad et al. (2012, p. 739) point out that a shift from hierarchy to actor-oriented organizational designs is characterized by the ability of the organizational actors to dynamically form collaborative relationships that rely on selforganization and local decision-making. New collaborative organizational forms employ infrastructures, commons and protocols to organize resources involving the key organizational actors, and they represent a promising source for business model innovation (Fjeldstad and Snow, 2018). The need for flexibility and specialization can lead firms to adapt and dynamically change their organizational design. Organizational actors can manage a variety of initiatives, overcoming hierarchy and resorting to organizational forms aimed at managing a project or solving a problem and then returning to the previous hierarchical configuration. Therefore, new organizational forms, which differ from the traditional hierarchical model, can informally and temporarily emerge to innovate the business model. Interpersonal relationships influence the success of business to business relationships and how managers collaborate and interact in problem solving activities that facilitate the business model innovation process. However, we still lack a theoretical understanding of the effects of the interpersonal relationship disruptions (Schmitz et al., 2020) and how intra-organizational networks between individuals coexist or are mutually exclusive and what characteristics of the organization affect the establishment of dissonant ties (Brennecke, 2019). Research investigating the effects of diversity on the innovation process has achieved mixed results and the need to explore the different dimensions of diversity has been highlighted (Schubert and Tavassoli, 2020).

Advice network relationships within organizations have been recognized as particularly important to promote innovation (Perry-Smith and Mannucci, 2017), because the exchange of advice between individuals enables the innovation process (Schneckenberg et al., 2019). For Rogan and Mors (2014, p. 1864), "informal ties are the result of nonprescribed social interaction processes and have been found to be more critical than formal ties when managers need to go outside existing boundaries." Intra-organizational advice networks are considered "powerful coordination mechanisms capable of crosscutting the formal boundaries of organizational units" (Lomi et al., 2014, p. 438), and their development and structuring depend on the purpose of the exchange. The advice exchange might facilitate the recombination of knowledge for developing innovative ideas; as illustrated by Kilduff and Krackhardt (2008), advice networks can be considered the main sources of knowledge and information within 
EJIM

24,4

\section{2}

organizations, which is therefore vital for the innovation process. According to Lomi et al. (2014), intra-organizational advice networks support knowledge transfer in three ways: they provide information aimed to solve problems that require different kinds of expertise and knowledge sources; they allow to detect where relevant knowledge is located within organizations; they encourage the exchange of opinions among individuals operating in different organizational units, divisions, or functions. Previous studies have demonstrated the importance of social networks for innovation (Aalbers and Dolfsma, 2015; Brennecke and Rank, 2017), as they lead to the creation of a social infrastructure that increases the probability of developing new ideas (Burt, 2004).

However, establishing advice exchange networks is not a linear process. Organizational boundaries are usually constituted to support specialization within units or functions, where socialization often occurs between individuals sharing similar knowledge bases. Firms can facilitate the advice exchange process, but the use of top-down and hierarchical decisions might not always be successful. In this vein, the introduction of an actor-oriented scheme where "control and coordination are based on direct exchanges among the actors themselves rather than by hierarchical planning" (Fjeldstad et al., 2012, p. 739) can be aimed to developing business model innovation (Figure 1). The transition to an actor-oriented architectural scheme requires the following three elements (Fjeldstad et al., 2012, p. 739): "(1) actors who have the capabilities and values to self-organize; (2) commons where the actors accumulate and share resources; and (3) protocols, processes, and infrastructures that enable multi-actor collaboration." The capability to span internal boundaries to support collaborative thinking and self-organize one's activities leads to considering that organizational role constraints can be overcome. Individuals that are able to self-organize on different projects lead to the development of new organizational designs (Benkler, 2002). However, the opportunity to create new forms of interactions and to be creative should not be bounded by the organizational structure: as pointed out by Salmimaa et al. (2018), managers who are in charge of the innovation process can be limited by their organizational role, which could have a negative impact on their work. Managers should be capable to self-organize their activities without being influenced by their formal roles to activate an actor-oriented scheme exchanging advice aimed to innovate the business model. This should be legitimate for any
Figure 1.

Theoretical model.

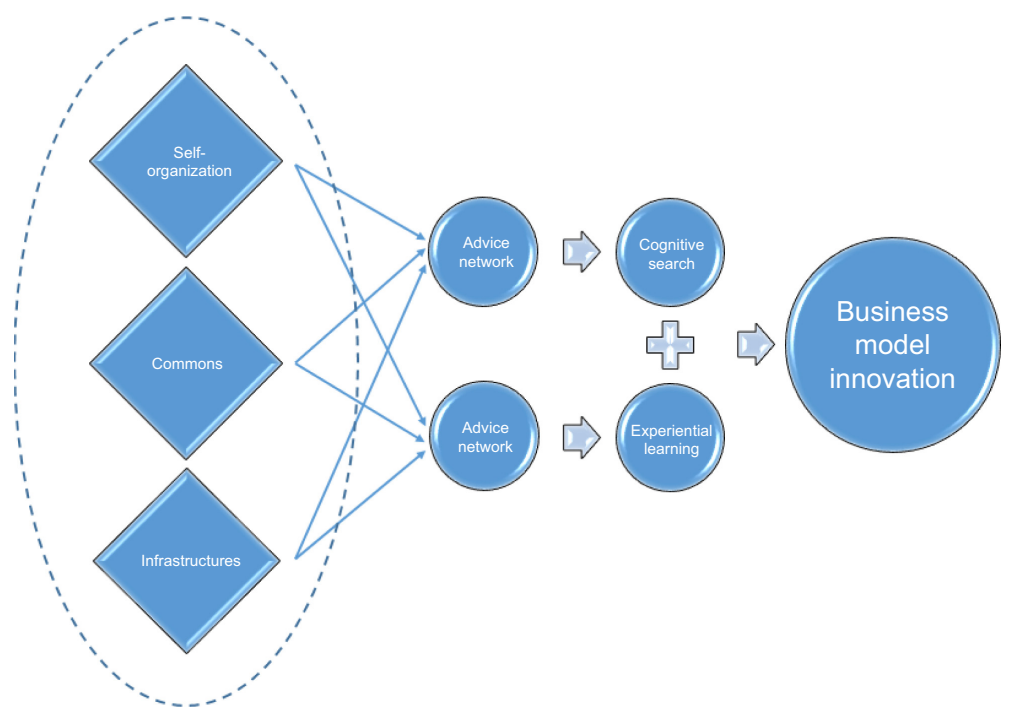


mechanisms of organizational learning to manage business model components, since business model innovation must be seen as the sum of cognitive representations and organizational actions based on experience (Berends et al., 2016); therefore, the advice exchange related to both cognitive search and experiential learning mechanisms needs to be unencumbered by the influence of the organizational role. Thus:

Hp1. Formal organizational roles do not influence advice networking (related to cognitive search and experiential learning mechanisms) aimed to develop business model innovation.

Another element characterizing the establishment of an actor-oriented scheme is the presence of commons, which are defined by Hess and Ostrom (2007, p. 13) as "a shared resource that is vulnerable to social dilemmas." Individuals create and share knowledge resources through interactions and the development of commons that address organizational issues such as equity and efficiency. The idea of commons is not a synonymous with open access, but it is mainly connected to the idea that individuals interact following certain social dynamics in a pre-defined institutional arrangement (Hess and Ostrom, 2007). Setting commons where individuals accumulate and share resources is strictly related to the presence of similar relational patterns: individuals with a similar position in the network are highly interdependent (Scott and Carrington, 2011). Managers showing similar relational patterns are more likely to establish connections (de Oliveira Maciel and Netto, 2020), thus creating common collective resources through the exchange of advice. In this respect, commons are relevant for business model innovation, because they set a sort of knowledge baseline which allows the coordination of organizational members' behavior. As highlighted by Cestino and Matthews (2016, p. 27), "common knowledge allows individuals to share and integrate aspects of knowledge that is particular to others," and intra-organizational advice networks assist knowledge sharing in this respect. The organizational learning modes of cognitive search and experiential learning are considered equally important in the business model innovation process; therefore, the presence of commons can support the establishment of an actor-oriented scheme when considering their mechanisms (conceptualization, creation, adaptation, and experimentation). Hence, we conjecture that:

Hp2. Commons positively influence advice networking (related to cognitive search and experiential learning mechanisms) aimed to develop business model innovation.

Finally, infrastructures (a categorization that includes protocols, processes and physical infrastructures, according to the definition of Fjeldstad et al., 2012) are crucial for connecting managers. They are necessary for the development of new solutions within the firm, because they make it possible to create systems for "effectively and efficiently connecting potential collaborators within the organization" (Fjeldstad et al., 2012, p. 740). Protocols and processes are created by the codification of labor activities; physical infrastructures refer to the units, centers or plants, where activities are performed. Sometimes standardized protocols and processes can be perceived as barriers for business model innovation (Bocken and Geradts, 2019). However, collaborating on innovation projects that require to follow similar internal protocols and processes can increase trust between managers (Grigoriou and Rothaermel, 2014), which is a positive driver for of actor-oriented scheme aimed to developing business model innovation (Santos et al., 2009). Moreover, physical infrastructures are relevant in the business model innovation process, because physical distance influences the quality and the quantity of interactions between individuals in charge of developing a new business model. Working closely support the establishment of actor-oriented scheme, because of the easiness in contacting managers for receiving, or providing, advice. Infrastructures (protocols, processes, and physical infrastructures) are important in both organizational learning modes of cognitive search and experiential learning (Berends et al., 2016); therefore, we expect that:
Overcoming hierarchy in business model innovation

1063 
EJIM

24,4
Hp3. Infrastructures positively influence advice networking (related to cognitive search and experiential learning mechanisms) aimed to develop business model innovation.

\section{Data and methodology}

\subsection{Context and data collection}

This study uses original data from Coopselios, a multi-unit leading cooperative firm specialized in personal care services that operates in Northern and Central Italy. Cooperative firms are particularly relevant in the Italian context: they cover a large portion of the demand for social services, while employing individuals with multiple expertise in different areas (Borzaga and Galera, 2016). Coopselios supplies services to over 7,000 people on a daily basis in the following areas: Elderly Sector, Disabled People Sector, Child Sector, Minors Sector, and Healthcare Sector. Such complex structure implies specialization and cooperation among units and a continuous exchange of knowledge between individuals.

In 2016, this firm started a process of business model innovation, in order to introduce new health services and entering into new market niches. This process was carried out for around one year and it involved all the 136 cooperative managers in the design and the implementation of the business model, because of their role as facilitators for the diffusion of knowledge needed (Basile and Faraci, 2015; Schneckenberg et al., 2019). Data related to the managers were collected using an online questionnaire between December 2017 and March 2018; managers were contacted by e-mail by the human resources (HR) department staff, which shared with them the link to the questionnaire and supported the research team in the second and third rounds of recall. Privacy issues were addressed before the creation of the questionnaire together with the Chief for the HR department.

The questionnaire included two sections: a section dedicated to collecting personal information on age, organizational role, educational level, involvement in innovative projects (with formal tasks), past and present working activities, and tenure of the managers (Section 1) and a section for mapping their intra-organizational advice networks (Section 2). Intraorganizational network data have been collected using a roster method (Scott and Carrington, 2011); the complete list of managers (roster) have been presented in a matrix in Section 2, and respondents could report the exchange of advice with others, by specifying the type of advice and its direction (i.e. if the respondent received or provided advice). To define the type of advice exchange, we asked to indicate if the advice was targeted to one or more of the following mechanisms (Berends et al., 2016):

(1) mechanisms linked to cognitive search: exchange of advice regarding the development of ideas and concepts related to the new business model ("conceptualization") and the realization of one or more of its components ("creation");

(2) mechanisms linked to experiential learning: exchange of advice regarding the adaptation ("adaptation") and the experimentation of the new business model ("experimentation").

We received 102 questionnaires from 136 managers, yielding a response rate of $75 \%$. An anonymized version of the questionnaire is illustrated in the Appendix; because of the privacy issue, Section 2 of the Appendix shows a reduced version of the roster used for network data collection.

\subsection{Methodology}

In order to test our hypotheses, we use SNA. SNA is a methodological approach for quantitatively analyzing social relations between a set of actors; according to Mitchell's 
definition, social networks are "a specific set of linkages among a defined set of persons, with the additional property that the characteristics of these linkages as a whole may be used to interpret the social behavior of the persons involved" (Mitchell, 1969, p. 2). SNA is increasingly used by researchers and practitioners to investigate relational patterns between individuals within organizations (Monaghan et al., 2017), because, as illustrated in the introduction and the theoretical framework, intra-organizational networks are important for developing innovation within an organization (e.g. Aalbers and Dolfsma, 2015; Brennecke and Rank, 2017), and SNA provides the statistical tools for their analysis.

The unit of analysis in SNA is the dyad, i.e. a pair of actors and their relationship. This dyadic perspective assumes the presence of interdependency between actors, which is completely different from the classical econometric approach, where actors are considered independent to each other (Scott and Carrington, 2011).

Since we focus on two different types of intra-organizational advice networks (related to cognitive search and experiential learning), we define two dependent variables for our analysis, observing:

(1) the presence of a relationship related to cognitive search: an advice exchange between two managers (a dyad) regarding the development of ideas and concepts related to the new business model ("conceptualization") and the realization of one or more of its components ("creation");

(2) the presence of a relationship related to experiential learning: an advice exchange between two managers (a dyad) regarding the adaptation ("adaptation") and the experimentation of the new business model ("experimentation").

Managers were asked to indicate in the online questionnaire if they received and/or provided advice on these four mechanisms ("conceptualization," "creation," "adaptation" and "experimentation" of the new business model) from/to the others. The "cognitive search" dependent variable is created by aggregating, for each dyad $i j$ made by actor $i$ and actor $j$, the exchanges reported by each one of the two respondents regarding the advice for the "conceptualization" of the business model and for its "creation." This variable is coded as 1 if $i$ declared that she/he received advice from actor $j$ for the "conceptualization" of the business model and for its "creation," and $j$ declared that she/he provided these types of advice. At the same time, this variable is coded as 1 if $i$ declared that she/he provided advice from actor $j$ for the "conceptualization" of the business model and for its "creation," and $j$ declared that she/he received these types of advice. In all other cases (no exchanges between $i$ and $j$, or only one type of advice exchanged), this variable is coded as 0 . The final output is a non-symmetric square matrix, since the value of the cell $i j$ can be different from $j i$. The "experiential learning" dependent variable is created following the same procedure but using the advice exchanges focused on the mechanisms of "adaptation" and "experimentation" of the new business model. Thus, we have two $102 \times 102$ non-symmetric squares matrices as (binary) dependent variables.

As explanatory variables for addressing our hypotheses, we concentrate on the elements of the actor-oriented scheme that enable managers' relationships: (1) the capabilities to selforganize; (2) commons; (3) protocols, processes and infrastructures (Fjeldstad et al., 2012). These elements are operationalized by using the following dyadic covariates: "apical"; "role"; "structural"; "province"; "innovativeness".

"Apical" and "role" are connected to the capabilities of the managers to self-organize. As pointed out by Fjeldstad et al. (2012), managers adopting an actor-oriented scheme should be able to minimize the influence of use of hierarchical roles. "Role" takes values equal to 1 if two managers have the same organizational role, 0 otherwise; "apical" takes values equal to 1 if two individuals are both apical managers according to the organization chart and the
Overcoming hierarchy in business model innovation

1065 
EJIM

24,4

1066

information provided by the Chief for the HR Department. There are seven possible categories of managers: coordinators; project managers; directors; the president of the firm; managers in charge of organizational function; senior manager in charge of production function; specialists. The president of the firm and most of the directors are considered apical managers.

"Structural" is used for operationalizing the commons. Fjeldstad et al. (2012, p. 739) define commons as the "resources that are collectively owned and available to the actors." Therefore, we rely on a measure of networking similarity (i.e. the structural equivalence) to detect managers who share similar network patterns, which are likely to have access to similar shared knowledge. Dyadic structural equivalence is measured by the correlation coefficient of the relationships shown by two managers (de Oliveira Maciel and Netto, 2020); since we observe two intra-organizational advice networks, we have two different matrices for "structural," one for the advice network related to cognitive search and one for that related to experiential learning. Explanatory variables' matrices are symmetric, i.e. the value of $i j$ is equal to the value of $j i$.

"Province" is related to protocols, processes and infrastructures, i.e. those systems that allow individuals to be connected. Working in physical structures located in the same Italian province can favor networking; "province" is coded as 1 if two managers work in the same province, 0 otherwise. Also "Innovativeness" is linked to protocols, processes and infrastructures: this covariate takes values equal to 1 if two managers are involved in projects for developing innovative products or activities other than business model innovation, 0 otherwise (see Appendix: Section 1, question 6).

As control variables, we use the following managers' attributes: age; gender; educational level; tenure. In SNA, continuous covariates are transformed to express the difference between dyad members. The dyadic covariate "age" for $i j$ is the result of the difference between the age of $i$ and the age of $j$. The same procedure applies, in our study, to the dyadic covariate "tenure," which is the difference between the number of years worked by $i$ and the number of years worked by $j$ in the cooperative. Regarding the categorical covariates, they are transformed into dummy variables which are equal to 1 if dyad actors belong to the same category, 0 otherwise. The categorical covariate "gender" is coded as 1 if two managers have the same gender, 0 otherwise; the categorical covariate "education" is coded as 1 if $i$ and $j$ have the same qualification, 0 otherwise. All the square matrices related to these control variables are symmetric: the value in the cell $i j$ is equal to the value in $j i$.

Our models are based on the LR-QAP, which is applied to network data when the dependent variable is binary. As other procedures from the QAP family, it uses permutation tests in a linear regression setting when (network) data are in square matrices, by overcoming the independence assumption problem from dyadic observations, which is not accomplished for network data by definition (Scott and Carrington, 2011).

The analysis is carried out using Ucinet 6 software (Borgatti et al., 2002).

\section{Results}

The intra-organizational networks of advice exchange related to cognitive search and experiential learning are illustrated in Figures 2-3. These networks are highly correlated (0.766), which indicates the presence of similar behavioral patterns irrespective of the mechanisms discussed in the advice exchange. The resulting graphs highlight that coordinators (circle nodes) are mostly located in the boundaries, while directors (up triangle nodes) are strategically central. The coordinators mainly receive advice from the top managers (i.e. the president of the cooperative and the directors), which is coherent with their role: during the development of the business model innovation, they receive ideas and knowledge that must be operatively translated into practice. 


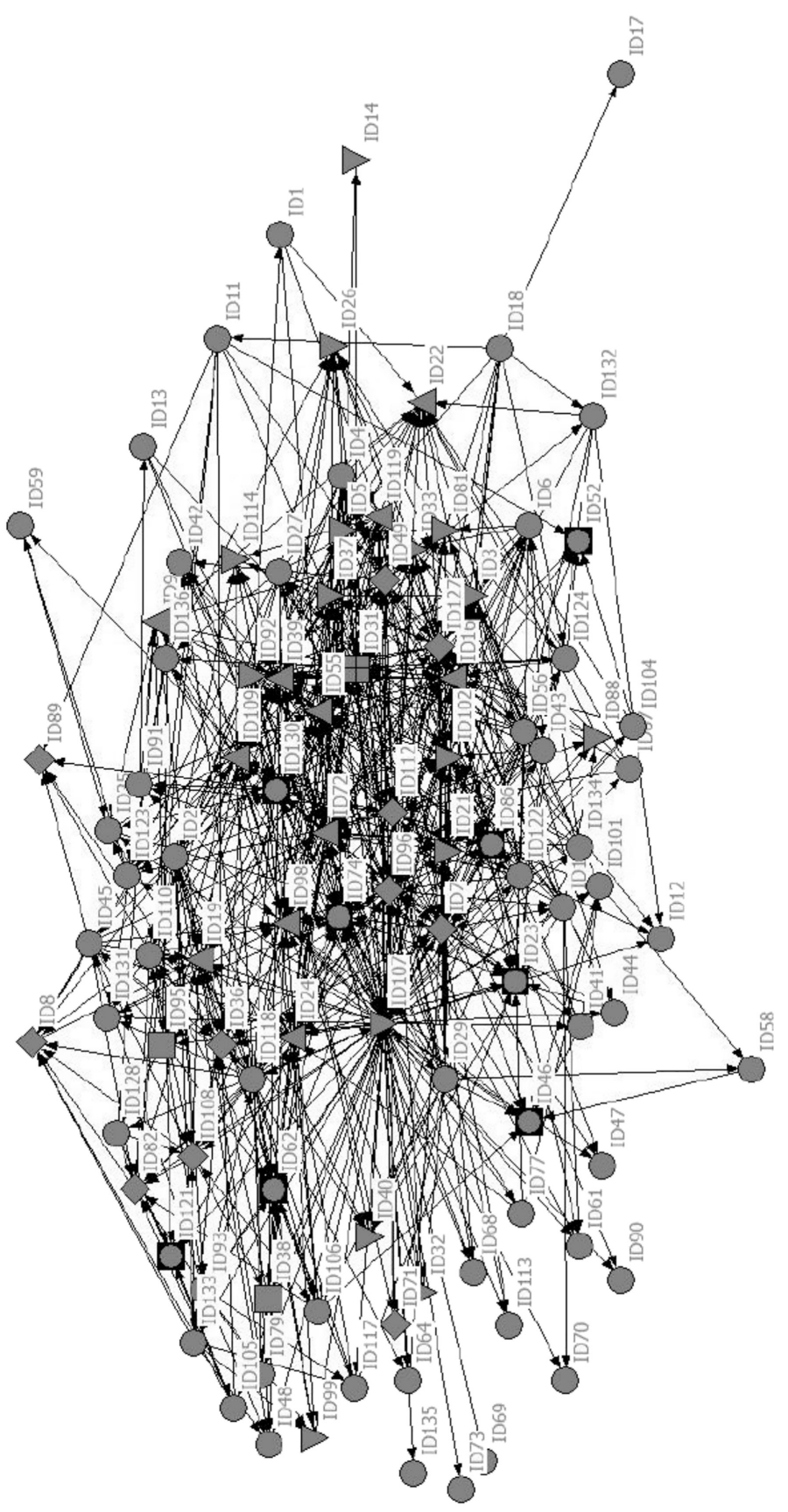

Overcoming hierarchy in business model innovation

1067

Figure 2. Cognitive search network 
\begin{tabular}{l} 
EJIM \\
24,4 \\
$\mathbf{1 0 6 8}$ \\
\hline
\end{tabular}

Figure 3.

Experiential learning network

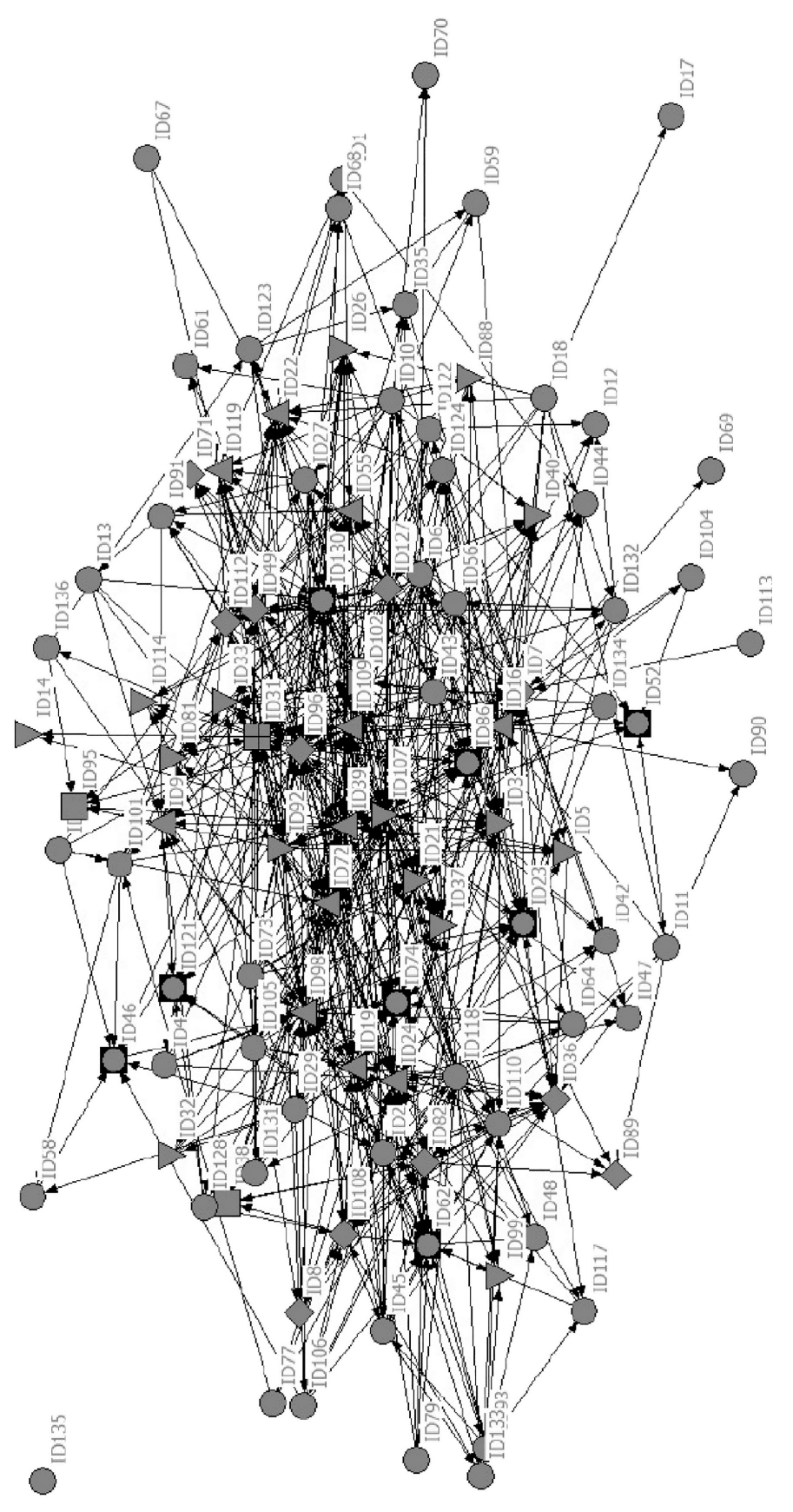


Legend: coordinators $=$ circle nodes; project managers $=$ square nodes; directors $=$ up triangle nodes; president $=$ box node; managers in charge of organizational function $=$ down triangle nodes; senior managers in charge of production function = circle-in-box nodes; specialists $=$ diamond nodes.

On average, managers have 7.3 advice relationships in the cognitive search network and 6.9 in the experiential learning network. Tables 1 and 2 illustrate the descriptive statistics and the QAP correlation for the explanatory and control variables used in the LR-QAP models. We use the QAP correlation because the assumption of independence between observations hierarchy in business model innovation does not hold for dyadic network data: hence, it is not possible to estimate the classical Pearson correlation (Scott and Carrington, 2011). The respondents are mainly female (76\%), highly involved in innovative activities other than business model innovation (63\%), working for the cooperative from around 11 years. Managers are extremely specialized: most of them has a degree in humanities and a quarter of the respondents has a $\mathrm{PhD}$ or a specialization, which could be a prerequisite for a more entrepreneurial perspective that facilitate the innovative process.

\begin{tabular}{|c|c|c|c|c|c|c|}
\hline & Type & Mean & $\mathrm{SD}$ & Min & Max & \\
\hline Age & Continuous & 44.25 & 8.45 & 27 & 66 & \\
\hline Gender & Dummy $(0=$ women; $1=$ men $)$ & 0.24 & 0.43 & 0 & 1 & \\
\hline Education & Categorical & $\begin{array}{l}\text { High s } \\
\text { degree } \\
\text { High } \\
\text { degree } \\
\text { High s } \\
\text { degree } \\
\text { High s } \\
\text { degree } \\
\text { BSc/M } \\
\text { scienc } \\
\text { BSc/M } \\
\text { scienc } \\
\text { BSc/M } \\
\text { humar } \\
\text { PhD o } \\
\text { specia }\end{array}$ & $\begin{array}{l}\text { hool p } \\
=6.86 \\
\text { hool s } \\
=1.96 \\
\text { hool t } \\
=7.8 \\
\text { hool h } \\
=1.96 \\
\text { cc in s } \\
\text { s = } 17 \\
\text { ic in n } \\
\text { s = } \\
\text { ic in } \\
\text { ities } \\
\text { sation }\end{array}$ & $\begin{array}{l}\text { rofess } \\
\% \\
\text { cientifi } \\
\% \\
\text { chnici } \\
\% \\
\text { umani } \\
\% \\
\text { cial } \\
65 \\
\text { atural } \\
0 \% \% \\
28.43 \\
=25 .\end{array}$ & $\begin{array}{l}\text { onal } \\
\text { ies } \\
\% \\
9 \%\end{array}$ & \\
\hline Tenure & Continuous & 11.12 & 8.39 & 1 & 32 & \\
\hline Apical & $\begin{array}{l}\text { Dummy }(0=\text { non apical manager; } 1=\text { apical } \\
\text { manager }\end{array}$ & 0.14 & 0.35 & 0 & 1 & \\
\hline Role & Categorical & \multicolumn{5}{|c|}{$\begin{array}{l}\text { Coordinator } \\
\text { Project manager } \\
\text { Director } \\
\text { President } \\
\text { Manager in charge of } \\
\text { organizational function } \\
\text { Senior manager in charge of } \\
\text { production function } \\
\text { Specialist }\end{array}$} \\
\hline Structural (cognitive search) & Continuous & 2.33 & 1.50 & 0 & 10.2 & \\
\hline $\begin{array}{l}\text { Structural (experiential } \\
\text { learning) }\end{array}$ & Continuous & 2.30 & 1.41 & 0 & 8.6 & \\
\hline Province & Categorical & 15 diff & rent $\mathrm{p}$ & ovinc & & rabe \\
\hline Innovativeness & Dummy $(0=$ not involved; $1=$ involved $)$ & 0.63 & 0.49 & 0 & 1 & Descriptive statistics \\
\hline
\end{tabular}


EJIM

24,4

1070

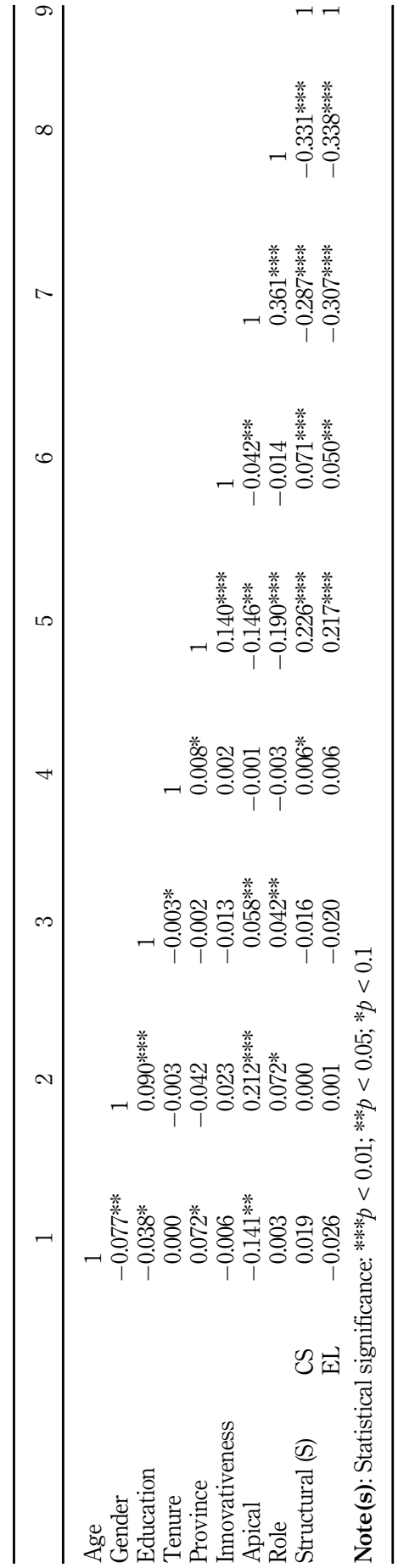

Table 2.

QAP correlations (dyadic matrices) 
The results of the LR-QAP models are illustrated in Table 3. Models 1 and 3 control for "age," "gender," "education" and "tenure"; models 2 and 4 include also the explanatory variables related to the elements of the actor-oriented scheme: "apical"; "role"; "structural"; "province"; "innovativeness."

By looking at the control variables, we find that "age" has a negative effect on the likelihood of people exchanging advice to innovate the business model. Especially when considering experiential learning, the greater the difference in age, the less likely the members of the organization will exchange advice to collaborate on the innovation of the business model. As an example, the greater ability to use digital technologies of younger generations can condition the collaboration between individuals of different ages, thus influencing the structure of intra-organizational linkages and, as a consequence, the outcome of the process of business model innovation. About the other control variables, we do not find statistically significant results with respect to "gender," "education" and "tenure."

The results of models 2 and 4 are used to test our hypotheses. The number of observations $(10,302)$ reflects the dyadic level of analysis, because there are $((102) *(102-1))$ possible dyads in the advice networks. The explanatory power ( $R$-squared) for each logistic regression is not particularly high, since it never overcomes $8.8 \%$, but it increases when adding more variables to the models, as expected.

Having the same organizational "role," as well as sharing the affiliation to the group of "apical" managers, does not influence the establishment of advice relationships between managers, neither for cognitive search nor for experiential learning mechanisms. The formal organizational features of the firm, related to the managers' organizational roles, do not reduce the flexibility in the choices of collaboration aimed to adapt and change the business model. Hence, we can say that Hp1 is confirmed, since managers activate an actor-oriented scheme by exchanging advice (for conceptualizing, creating, adapting, and experimenting the novel business model) without being influenced by their formal roles. The coefficients for "structural" are positive and statistically significant, both for the cognitive search and the experiential learning network: the more two managers share similar network patterns, the more they are likely to activate an actor-oriented scheme exchanging advice aimed to business model innovation. Therefore, the positive effect of commons on the establishment of an actor-oriented scheme to develop business model innovation (Hp2) is confirmed. In particular, this effect has the same intensity in both advice networks, which means that the influence of commons does not change when managers establish an actor-oriented scheme for conceptualizing/creating the new business model or, on the other hand, they exchange advice

\begin{tabular}{|c|c|c|c|c|c|}
\hline & \multicolumn{2}{|c|}{ Cognitive search network } & \multicolumn{2}{|c|}{ Experiential learning network } & \\
\hline & Model 1 & Model 2 & Model 1 & Model 2 & \\
\hline Intercept & -2.539 & -5.628 & -2.488 & -5.597 & \\
\hline Age & -0.014 & $-0.022^{* *}$ & $-0.023^{* * *}$ & $-0.026^{* *}$ & \\
\hline Gender & 0.162 & 0.169 & 0.134 & 0.186 & \\
\hline Education & 0.048 & 0.046 & -0.015 & 0.002 & \\
\hline Tenure & -0.009 & -0.010 & -0.005 & -0.006 & \\
\hline Apical & & 0.014 & & -0.043 & \\
\hline Role & & -0.081 & & -0.017 & \\
\hline Structural & & $0.522^{* * * *}$ & & $0.562^{* * *}$ & \\
\hline Province & & $0.625^{* * * *}$ & & $0.595^{* * * *}$ & \\
\hline Innovativeness & & $0.322^{* * * *}$ & & $0.289 * * *$ & \\
\hline$L L$ & $-2,667.714$ & $-2,333.390$ & $-2,552.357$ & $-2,280.395$ & Table 3. \\
\hline$R$-squared & 0.002 & $0.088^{* * * *}$ & 0.002 & $0.063^{* * * *}$ & Results of the LR-QAP \\
\hline \multicolumn{5}{|c|}{ Note(s): Statistical significance: $* * * p<0.01 ; * * p<0.05 ; * p<0.1$} & models \\
\hline
\end{tabular}

Overcoming hierarchy in business model innovation 
EJIM

24,4

1072

for its adaptation/experimentation. Finally, Hp3 is confirmed by the results for "province" and "innovativeness." Working in physical structures geographically close ("province") has a positive and statistically significant effect on the exchange of advice between managers. This effect is stronger for cognitive search, i.e. for the conceptualization and the creation of the new business model. Furthermore, a positive and statistically significant effect is observed also for "innovativeness," even if lower compared to "province": having participated to common innovative processes (others than innovating the business model) supports the activation of an actor-oriented scheme. This effect is greater in the advice network related to cognitive search mechanisms, probably because for business model conceptualization and creation the need for close interactions is stronger.

\section{Discussion and conclusions}

This study responds to recent calls for research to enhance our theoretical understanding of business model innovation (Foss and Saebi, 2017; Massa and Tucci, 2014; Zott et al., 2011), advancing our knowledge on how business model innovation interacts with adaptation and change of the firm's organizational structure. We find that organizational actors, when engaged in activities aimed at developing business model innovation, can move from the extant hierarchical structure to a different organizational design which facilitate information exchange and, thus, collaboration within the firm. This research, specifically, provides empirical support to recent theories addressing the actor-oriented architectural scheme for improving collaboration within organizations and suggests new insights on its implementation in the process of business model innovation. Our findings provide several contributions to the literature on business model innovation.

First, this research provides empirical support to the theorization of the actor-oriented scheme as a structure implemented by firms to enable intra-organizational collaboration. Fjeldstad et al. (2012) theorized the actor-oriented architectural scheme to explain the emergence of new organizational designs that go beyond the traditional hierarchical structure, in order to deal more effectively with dynamic and complex environments. However, empirical research on this topic has so far been very limited.

The weaknesses of the hierarchical structure have been extensively debated by previous literature. It has been argued that hierarchy facilitates the reliable execution of well-known tasks, but it hampers activities that may require rapid change (Hamel, 2007) or solving complex and non-routine problems, especially those that affect cross-functional boundaries (Adler, 2001). Strictly formal hierarchical organizations show limitations in gaining access to the variety of knowledge and experience needed to tackle competitive challenges. Coordination and control activities are traditionally based on hierarchy, but this mechanism can delimit and reduce potential collaboration between organizational members (Majchrzak et al., 2007). Therefore, hierarchy's shortcomings seem extremely critical in today's highly dynamic and turbulent environment. Alternative ways of organizing have been explored (Majchrzak et al., 2007), but a comprehensive view of how hierarchybased organizational structures can be reduced or replaced has not yet been achieved by the extant research. The results of our research add new insights to the debate on how different organizational structures, alternative to hierarchy or less hierarchical (Lee and Edmondson, 2017), can be effective in innovation pathways or in addressing uncertainty and change. The actor-oriented scheme construct has been suggested as a new and promising way for organizing in a multiparty collaboration perspective (Fjeldstad and Snow, 2018). This scheme responds to the firms' need to leverage widespread knowledge and expertise to create innovative solutions and fast reactions to cope with emerging challenges (Ancona et al., 2002; Martin et al., 2013). By concentrating on the managers' networks of advice exchange (Figures $2-3$ ), and distinguishing between exchanges focused on mechanisms related to cognitive 
search and experiential learning (Berends et al., 2016), we confirm the existence of the key elements of the actor-oriented scheme consisting of (1) actors who have the capacity to selforganize, (2) commons and (3) infrastructures that enable multi-actor collaboration. Therefore, we contribute to the advancement of the extant research by providing empirical support to the theorization of the actor-oriented scheme as a way of organizing that enables intra-organizational collaboration in a multi-actor perspective.

Second, this research finds that the actor-oriented architectural scheme interacts with the process of business model innovation. Prior studies emphasized the need for new organizational designs to leverage accumulating knowledge and tackle complex challenges. It has been suggested that new organizational designs should be built on business models that identify new ways of creating and appropriating value through the combination of knowledge distributed among individuals, as well as organizational forms that effectively manage knowledge resources (Miles et al., 2010, p. 97). Scholars investigated how alternative organizational forms may be used to coordinate socially responsible activities (Husted, 2003) or to make organizations that interact with digital technologies effective (Snow et al., 2017). Our findings shed light on how firms develop and change their organizational structures when innovating their business model. Fjeldstad and Snow (2018) emphasize the organizational architecture as an essential component of future business model research and point out the need to advance our knowledge on how interpersonal and intra-organizational collaboration work. We argue that managers, when interacting in order to generate business model innovation, may overcome the boundaries of the hierarchical structure and move towards an actor-oriented scheme (Fjeldstad et al., 2012), which allows greater individual flexibility in choosing with whom to collaborate and lower intermediation by formal structures. Therefore, the implementation of the actor-oriented scheme turns out to be an effective organizational design because it facilitates experimentation which represents a recognized source of learning that, in turn, feeds the process of business model innovation (Achtenhagen et al., 2013; Andries and Debackere, 2013; Berends et al., 2016; Doz and Kosonen, 2010). Similarly, scholars recognize the role of cognition in managerial decisions related to business model innovation (Doz and Kosonen, 2010) and its influence in changing, adapting and transforming resources to innovate the business model. Accessibility to different learning modes positively influences the innovation of the business model and helps to explain why members of the organization leave the hierarchical structure and move towards the actor-oriented scheme.

We find that managers self-organize and develop networking relationships to exchange advice without being constrained by their organizational role and hierarchical position. Fjeldstad et al. (2012, p. 739) argue that the members of an organization can self-organize when they have the skills, tools and values to define objectives and assess the effects of their actions on the achievement of those objectives. This definition seems to associate selforganization with the capacity to plan objectives and actions to achieve them in a way that is different from hierarchy or with minimal use of hierarchical mechanisms. Focusing on the process of business model innovation, our research analyses the networks through which managers exchange advice by the organizational learning mechanisms of cognitive research (conceptualization and creation), consistent with planning activities and our results provide empirical support to the construct. However, we have gone one step forward by investigating the network through which managers exchange advice related to the alternative mechanisms of experiential learning (adaptation and experimentation), consistent with "learning by doing" activities. Our results confirm, in the process of business model innovation, the propensity to develop relationships through self-organization and without the constraint of hierarchical coordination. They also advance our knowledge of the interdependencies and complementarities that characterize the business model architecture (Foss and Saebi, 2017). Therefore, by focusing the research on the process of business model innovation, our results
Overcoming hierarchy in business model innovation

1073 
EJIM

24,4

1074

empirically support the construct proposed by Fjeldstad et al. (2012) and extend it, adding empirical support to collaboration aimed to foster experiential learning. Similarly, we find that commons, identified by the presence of similar structural patterns, facilitate the implementation of the actor-oriented scheme for business model innovation. The existence of commons, such as shared knowledge, the value system, the adherence to and identification with the cultural models that characterize the community, facilitate the exchange of advice and strengthen the collaboration between the members of the organization, thus mitigating the formal conditioning of hierarchical relations (Hess and Ostrom 2007). We find a high significance of infrastructures (including protocols, processes, and physical infrastructures enabling multi-actor relationships, as defined by Fjeldstad et al., 2012) for the exchange of advice aimed at business model innovation. Working in geographically close physical infrastructures also means belonging to a certain community, which influences how organizations innovate their business model. Firms are rooted in their social environment and their activities are strongly oriented towards sustainability and to impact on the communities they belong to. Therefore, the firm's process of business model innovation is also oriented towards satisfying the needs expressed by a local community. We also find a positive effect of the involvement in innovative activities, i.e. similar protocols and processes, by managers as a driver of the exchange of advice aimed at business model innovation. Managers who share these activities show a higher propensity to exchange advice aimed at business model innovation, especially in a cognitive search approach. Our results have implications for understanding how the core-periphery relationships within organizations are shaped. The innovation of the business model is developed with the support of territorial infrastructures and the exchange of advice is not conditioned by the hierarchical structure.

Third, this research advances our understanding of the interaction between business model innovation and the firm's organizational design. Our findings show that the shift from the hierarchical organizational structure to the actor-oriented scheme is aimed at the process of business model innovation and, therefore, constitutes not a definitive, but a reversible organizational change. The process of business model innovation pushes the organizational structure to reiterated adaptation and change, depending on managers' objectives and tasks. As noted above, traditional hierarchical structures have shown weaknesses when faced with the need of timely and effective responses to emerging opportunities and challenges (Adler, 2001; Hamel, 2007). However, they remain prevalent in the coordination and control of ordinary activities. When exchanging advice to innovate the business model, the organization members switch to the actor-oriented scheme but they comply with the hierarchical structure when performing ordinary tasks and executing the current strategy. Previous literature suggested reconfigurable organizations as a way of organizing to respond to large opportunities (Galbraith, 2010), but a further insight of this research is the coexistence of different organizational structures that respond to contextually different needs in the functioning of the organization, or in its objectives or in its activities. The existing literature investigated the shift to organizational structures different from the hierarchy, but the reversibility of changes in the organizational structure has so far been neglected (Lee and Edmondson, 2017). We find that the innovation process of the business model can push the firm to implement ad hoc organizational designs contingent on the need for innovation. As firms innovate their business models through incremental or radical experimentation, the actor-oriented scheme turns out to be an effective organizational structure because it allows different approaches to learning to cope with ambiguities and complexity (Andries and Debackere, 2013). Firms face an increased business complexity, e.g. in terms of services delivered, markets served and geographical diffusion, and the organizational dynamism may lead to the coexistence of different structures. Hierarchy constitutes the formally adopted mechanism of coordination and control in the implementation of the current strategy. However, when trying to innovate the business model, managers interact by overcoming the 
organizational boundaries to meet significant emerging needs. Dynamism and complexity require the adaptation of the organizational structure, in order to simultaneously manage a range of different initiatives by interacting with others. Hence, organizational structures are not fixed, but they are triggered by individuals with a key role for the development of business model innovation. Therefore, this research extends previous knowledge showing how the dynamic adaptation to the environmental challenges may lead to the adoption of the actor-oriented scheme and the potential coexistence of different organizational models. Czarniawska (2013) argues that actions taken by an actor represent responses and consequences of actions previously taken by other individuals. However, to the best of our knowledge, this research is among the first studies that provide empirical evidence of the dynamic interaction between the process of business model innovation and the firm's organizational structure.

This research provides new insights, both in the academic debate and in the managerial arena, on how firms innovate their business models. We investigated a large and diversified firm and we find the emergence of an actor-oriented scheme that informally overcomes the traditional and well-established hierarchical structure. We argue that managers exchange advice by overcoming the boundaries of hierarchical structure and moving towards an actororiented scheme. Then, they can still rely on the formal hierarchical model for ensuring coordination and control (Galbraith, 1974). We advance the theoretical understanding of how the business model innovation and the firm's organizational design are intertwined by discussing potentially reversible shifts from hierarchical to actor-oriented organizational structures.

Further theoretical implications can be retained from the above insights. The literature on business model innovation can be enriched by the use of SNA applied to intra-organizational network structures (Soda and Zaheer, 2012; Kleinbaum et al., 2013), providing details on the tendency to establish and maintain connections between actors. Our insights contribute to recent literature where the network approach can add value to the investigation of work teams boundaries and, especially relevant, the concept of teaming (Park et al., 2020). Work teams may be considered not as composed by formal directives, but by naturally occurring patterns of relationships that may be transient in nature; hence, our results can be a useful insight to understand the mechanisms and drivers for the natural establishment of work teams, also temporary or reversible. Moreover, Schubert and Tavassoli (2020) address how innovation processes can be influenced by diversity, finding that diversity at the organizational level of top management teams has an effect on the firm's decision to be engaged in innovation activities, while diversity at the middle management level impacts on the actual outcome of the innovation process, especially on key elements of the business model such as product innovation and the degree of novelty in the marketplace.

In addition, the transformation from the hierarchical structure to the actor-oriented scheme represents a variation in the complementarities that define the architecture of the business model and drive its innovation (Foss and Saebi, 2017). Further research should investigate characteristics, enablers and obstacles of the transformation process and how they interact with business model innovation.

This research has managerial implications. The insights of this study might help managers to be aware of the usefulness of multiparty collaboration in the process of business model innovation. We confirm that an actor-oriented scheme can be effectively used to enhance intra-organizational collaboration in the process of business model innovation. Thus, managers should consider the implementation of the actor-oriented scheme to improve the organizational capability of business model innovation. They might learn how to improve organizational flexibility and, therefore, the ability to cope more effectively with different competitive challenges. For example, the observation of managers' advice exchange networks makes it possible to identify which individuals or organizational areas are mostly
Overcoming hierarchy in business model innovation

1075 
EJIM

24,4

involved in the innovation of the business model and which need to be stimulated instead. Flexibility and dynamic adaptation are crucial requirements for effective organizational design in order to promote business model innovation. The organizational design should support managers to establish specific network relationships for enabling them to acquire and develop new knowledge to innovate the business model. Thus, firms should create the conditions to facilitate the communication and exchange of knowledge between managers with different background and interests, at different hierarchical levels (Schubert and Tavassoli, 2020). Designing organizational patterns and facilities for collaboration can positively influence the availability and use of relevant knowledge, with positive effects on the process of business model innovation. However, the adoption of new organizational design may require new skills and competences and managers should consider investments in training activities for developing suitable organizational capabilities.

The flexibility of organizational structures for developing business models is an argument for managers interested in promoting innovation and business growth. Business model innovation is particularly relevant when external uncertainties foster radical changes in the logic of business management, rather than seeking improvements on how business is currently conducted. Overcoming the hierarchical model and introducing an alternative actor-oriented scheme, eventually reversible, offers great opportunities for achieving disruptive innovation, as it enables the acquisition of highly qualified skills to seize economic opportunities or to react to environmental threats. Firms operate in a dynamic and continuously evolving environment that requires the adaptation and renewal of the business model to strengthen survival and business development. Phenomena such as globalization, technological innovation and social development constantly modify the competitive game and both scholars and practitioners agree that firms with the fastest growth and aboveaverage performance are those that take advantage of these changes to innovate their business model and compete differently (e.g. Casadesus-Masanell and Ricart, 2010).

The novelty of this research relies on its attempt to empirically investigate the features of an actor-oriented scheme aimed to develop business model innovation. However, it suffers from three main limitations. First, since we use advice exchanges between individuals as network data, it is difficult to estimate the effect of the hierarchical control mechanisms in terms of efforts to establish networks. We can observe that managers are able to overcome their formal roles by establishing different relationships, but we cannot say anything about their intensity. A second limitation is related to the lack of information about the managers' utilization of the advice exchanged. Indeed, a manager could have received information of various importance, from its perspective, for the business model innovation process, and it could have used only those that it considered relevant for its work. Further developments can be dedicated to investigating in depth the exchange of advice, by using a mixed methods approach for analyzing qualitative data from interviews, which can provide detailed information about the importance of the advice exchanged. Third, since actor-oriented schemes consider the possibility that individual collaboration patterns change over time, a longitudinal study would provide a better understanding of the network evolution linked to the development of the business model innovation.

\section{References}

Aalbers, H.L. and Dolfsma, W. (2015), "Bridging firm-internal boundaries for innovation: directed communication orientation and brokering roles", Journal of Engineering and Technology Management, Vol. 36, pp. 97-115.

Achtenhagen, L., Melin, L. and Naldi, L. (2013), "Dynamics of business models-strategizing, critical capabilities and activities for sustained value creation", Long Range Planning, Vol. 46, pp. 427-442. 
Adler, P. (2001), "Market, hierarchy, and trust: the knowledge economy and the future of capitalism", Organization Science, Vol. 12 No. 2, pp. 215-234.

Amit, R. and Zott, C. (2001), "Value creation in e-business", Strategic Management Journal, Vol. 22, pp. 493-520.

Ancona, D., Bresnan, H. and Kaeufer, K. (2002), “The comparative advantage of X-teams”, MIT Sloan Management Review, Vol. 43 No. 3, pp. 33-39.

Andries, P. and Debackere, K. (2013), "Business model innovation: propositions on the appropriateness of different learning approaches", Creativity and Innovation Management, Vol. 22, pp. 337-358.

Appleyard, M.M. and Chesbrough, H.W. (2017), "The dynamics of open strategy: from adoption to reversion”, Long Range Planning, Vol. 50 No. 3, pp. 310-321.

Aspara, J., Lamberg, J.A., Laukia, A. and Tikkanen, H. (2013), "Corporate business model transformation and inter-organizational cognition: the case of Nokia", Long Range Planning, Vol. 46, pp. 459-474.

Basile, A. and Faraci, R. (2015), "Aligning management model and business model in the management innovation perspective: the role of managerial dynamic capabilities in the organizational change", Journal of Organizational Change Management, Vol. 28, pp. 43-58.

Benkler, Y. (2002), "Coase's penguin, or, Linux and the nature of the firm”, The Yale Law Journal, Vol. 112 No. 3, pp. 369-446.

Berends, H., Smits, A., Reymen, I. and Podoynitsyna, K. (2016), "Learning while (re)configuring: business model innovation processes in established firms", Strategic Organization, Vol. 14 No. 3, pp. 181-219.

Björk, J. and Magnusson, M. (2009), "Where do good innovation ideas come from? Exploring the influence of network connectivity on innovation idea quality", Journal of Product Innovation Management, Vol. 26 No. 6, pp. 662-670.

Bock, A.J., Opsahl, T., George, G. and Gann, D.M. (2012), "The effects of culture and structure on strategic flexibility during business model innovation", Journal of Management Studies, Vol. 49, pp. 279-305.

Bocken, N.M.P. and Geradts, T.H.J. (2019), "Barriers and drivers to sustainable business model innovation: organization design and dynamic capabilities", Long Range Planning, in press, doi: 10.1016/j.lrp.2019.101950.

Borgatti, S.P., Everett, M.G. and Freeman, L.C. (2002), Ucinet for Windows: Software for Social Network Analysis, Analytic Technologies, Harvard.

Borzaga, C. and Galera, D. (2016), "Innovating the provision of welfare services through collective action: the case of Italian social cooperatives", International Review of Sociology, Vol. 26 No. 1, pp. 31-47.

Brennecke, J. (2019), "Dissonant ties in intraorganizational networks: why individuals seek problemsolving assistance from difficult colleagues", Academy of Management Journal, in press, doi: 10. 5465/amj.2017.0399.

Brennecke, J. and Rank, O. (2017), “The firm's knowledge network and the transfer of advice among corporate inventors - a multilevel network study", Research Policy, Vol. 46 No. 4, pp. 768-783.

Burt, R.S. (2004), "Structural holes and good ideas", American Journal of Sociology, Vol. 110 No. 2, pp. 349-399.

Casadesus-Masanell, R. and Ricart, J.E. (2010), "From strategy to business models and onto tactics", Long Range Planning, Vol. 43, pp. 195-215.

Cestino, J. and Matthews, R. (2016), "A perspective on path dependence processes: the role of knowledge integration in business model persistence dynamics in the provincial press in England”, Journal of Media Business Studies, Vol. 13 No. 1, pp. 22-44. 
EJIM

24,4

1078

Crawford, E.R. and LePine, J.A. (2013), "A configural theory of team processes: accounting for the structure of task-work and teamwork", Academy of Management Review, Vol. 38, pp. 32-48.

Czarniawska, B. (2013), "Organizations as obstacles to organizing”, in Robichaud, D. and Cooren, F. (Eds), Organization and Organizing, Routledge, New York.

de Oliveira Maciel, C. and Netto, R.Z.R. (2020), "Architectural agency in intra-organizational networks”, Journal of Business Research, Vol. 109, pp. 489-497.

Demil, B. and Lecocq, X. (2009), "Business models evolution: towards a dynamic consistency view of strategy", Universia Business Review, Vol. 23, pp. 86-107.

Doz, Y.L. and Kosonen, M. (2010), "Embedding strategic agility: a leadership agenda for accelerating business model renewal", Long Range Planning, Vol. 43, pp. 370-382.

Eppler, M.J., Hoffmann, N.F. and Bresciani, S. (2011), "New business models through collaborative idea generation", International Journal of Innovation Management, Vol. 15, pp. 1323-1341.

Fjeldstad, Ø.D. and Snow, C.C. (2018), "Business models and organization design", Long Range Planning, Vol. 51, pp. 32-39.

Fjeldstad, Ø.D., Snow, C.C., Miles, R.E. and Lettl, C. (2012), "The architecture of collaboration", Strategic Management Journal, Vol. 33 No. 6, pp. 734-750.

Foss, N.J. and Saebi, T. (2017), "Fifteen years of research on business model innovation: how far have we come, and where should we go?”, Journal of Management, Vol. 43 No. 1, pp. 200-227.

Galbraith, J.R. (1974), “Organization design: an information processing view”, Interfaces, Vol. 4, No.3, pp. $28-36$.

Galbraith, J.R. (2010), "The multi-dimensional and reconfigurable organization", Organizational Dynamics, Vol. 39, No. 2, pp. 115-125.

Gatautis, R., Vaiciukynaite, E. and Tarute, A. (2019), "Impact of business model innovations on SME's innovativeness and performance", Baltic Journal of Management, Vol. 14 No. 4, pp. 521-539.

Gavetti, G. and Levinthal, D. (2000), "Looking forward and looking backward: cognitive and experiential search", Administrative Science Quarterly, Vol. 45 No. 1, pp. 113-137.

Gregory, B.T., Harris, S.G., Armenakis, A.A. and Shook, C.L. (2009), "Organizational culture and effectiveness: a study of values, attitudes, and organizational outcomes", Journal of Business Research, Vol. 62, pp. 673-679.

Grigoriou, K. and Rothaermel, F.T. (2014), "Structural microfoundations of innovation: the role of relational stars", Journal of Management, Vol. 40 No. 2, pp. 586-615.

Hamel, G. (2007), The Future of Management, Harvard Business School Press, Boston, MA.

Hatch, M.J. (1993), "The dynamics of organizational culture", Academy of Management Review, Vol. 18 No. 4, pp. 657-693.

Heikkilä, M., Bouwman, H. and Heikkilä, J. (2018), "From strategic goals to business model innovation paths: an exploratory study", Journal of Small Business and Enterprise Development, Vol. 25, No. 1, pp. 107-128.

Hess, C. and Ostrom, E. (2007), Understanding Knowledge as a Commons: From Theory to Practice, MIT Press, Cambridge.

Hock, M., Clauss, T. and Schulz, E. (2016), “The impact of organizational culture on a firm's capability to innovate the business model”, R\&D Management, Vol. 46 No. 3, pp. 433-450.

Hogan, S.J. and Coote, L.V. (2014), "Organizational culture, innovation and performance: a test of Schein's model”, Journal of Business Research, Vol. 67, pp. 1609-1621.

Homburg, C. and Pfesser, C. (2000), "A multiple-layer model of market-oriented organizational culture: measurement issues and performance outcomes", Journal of Marketing Research, Vol. 37 No. 4, pp. 449-462.

Husted, B.W. (2003), "Governance choices for corporate social responsibility: to contribute, collaborate or internalize?”, Long Range Planning, Vol. 36, pp. 481-498. 
Kelley, D.J., Peters, L. and O'Connor, G.C. (2009), "Intra-organizational networking for innovationbased corporate entrepreneurship", Journal of Business Venturing, Vol. 24 No. 3, pp. 221-235.

Khazanchi, S., Lewis, M.W. and Boyer, K.K. (2007), "Innovation-supportive culture: the impact of organizational values on process innovation", Journal of Operations Management, Vol. 25, pp. 871-884.

Kilduff, M. and Krackhardt, D. (2008), Interpersonal Networks in Organizations: Cognition, Personality, Dynamics, and Culture, Cambridge University Press, New York.

Kleinbaum, A.M., Stuart, T.E. and Tushman, M.L. (2013), "Discretion within constraint: homophily and structure in a formal organization”, Organization Science, Vol. 24 No. 5, pp. 1316-1336.

Lee, M.Y. and Edmondson, A.C. (2017), "Self-managing organizations: exploring the limits of less hierarchical organizing”, Research in Organizational Behavior, Vol. 37, pp. 35-58.

Lomi, A., Lusher, D., Pattison, P.E. and Robins, G. (2014), "The focused organization of advice relations: a study in boundary crossing”, Organization Science, Vol. 25 No. 2, pp. 438-457.

Majchrzak, A., Jarvenpaa, S.L. and Hollingshead, A.B. (2007), "Coordinating expertise among emergent groups responding to disasters", Organization Science, Vol. 18 No. 1, pp. 147-161.

Martin, S., Liao, H. and Campbell, E. (2013), "Directive versus empowering leadership: a field experiment comparing impacts on task proficiency and proactivity", Academy of Management Journal, Vol. 56 No. 5, pp. 1372-1395.

Martins, L.L., Rindova, V.P. and Greenbaum, B.E. (2015), "Unlocking the hidden value of concepts: a cognitive approach to business model innovation", Strategic Entrepreneurship Journal, Vol. 9 No. 1, pp. 99-117.

Massa, L. and Tucci, C.L. (2014), "Business model innovation", in Dodgson, M., Gann, D.M. and Phillips, N. (Eds), The Oxford Handbook of Innovation Management, Oxford University Press, Oxford, pp. 420-441.

Miles, R.E. and Snow, C.C. (1978), Organizational Strategy, Structure, and Process, McGraw-Hill, New York.

Miles, R.E., Snow, C.C., Fjeldstad, Ø.D., Miles, G. and Lettl, C. (2010), "Designing organizations to meet 21st-century opportunities and challenges", Organizational Dynamics, Vol. 39 No. 2, pp. 93-103.

Mitchell, J.C. (1969), “The concept and use of social networks”, in Mitchell, J.C. (Ed.), Social Networks in Urban Situations, University of Manchester Press, Manchester.

Mitchell, D. and Coles, C. (2003), "The ultimate competitive advantage of continuing business model innovation", Journal of Business Strategy, Vol. 24, pp. 15-21.

Monaghan, S., Lavelle, J. and Gunnigle, P. (2017), "Mapping networks: exploring the utility of social network analysis in management research and practice", Journal of Business Research, Vol. 76, pp. 136-144.

O'Reilly, C.A., III, Chatman, J. and Caldwell, D.F. (1991), "People and organizational culture: a profile comparison approach to assessing person-organization fit", Academy of Management Journal, Vol. 34 No. 3, pp. 487-516.

Park, S., Grosser, T.J., Roebuck, A.A. and Mathieu, J.E. (2020), "Understanding work teams from a network perspective: a review and future research directions", Journal of Management, pp. 1-27, in press, doi: 10.1177/0149206320901573.

Pauget, B. and Wald, A. (2018), "Creating and implementing organizational innovation: the role of professional identity and network embeddedness in healthcare organizations", European Journal of Innovation Management, Vol. 21 No. 3, pp. 384-401.

Perry-Smith, J.E. and Mannucci, P.V. (2017), "From creativity to innovation: the social network drivers of the four phases of the idea journey", Academy of Management Review, Vol. 42 No. 1, pp. 53-79.

Rogan, M. and Mors, M.L. (2014), "A network perspective on individual-level ambidexterity in organizations", Organization Science, Vol. 25 No. 6, pp. 1860-1877.
Overcoming hierarchy in business model innovation 
EJIM

24,4

1080

Saebi, T. and Foss, N.J. (2015), "Business models for open innovation: matching heterogeneous open innovation strategies with business model dimensions", European Management Journal, Vol. 33 No. 3, pp. 201-213.

Salmimaa, T., Hekkala, R. and Pekkola, S. (2018), "Dynamic activities for managing an IS-enabled organizational change”, Business and Information Systems Engineering, Vol. 60 No. 2, pp. 133-149.

Santos, J., Spector, B. and Van der Heyden, L. (2009), "Toward a theory of business model innovation within incumbent firms", INSEAD Working Paper Series, 2009/16/ST/TOM.

Schein, E.H. (1992), Organizational Culture and Leadership, Jossey-Bass, San Francisco.

Schmitz, C., Friess, M., Alavi, S. and Habel, J. (2020), "Understanding the impact of relationship disruptions”, Journal of Marketing, Vol. 84 No. 1, pp. 66-87.

Schneckenberg, D., Velamuri, V. and Comberg, C. (2019), "The design logic of new business models: unveiling cognitive foundations of managerial reasoning", European Management Review, Vol. 16, pp. 427-447.

Schubert, T. and Tavassoli, S. (2020), "Product innovation and educational diversity in top and middle management teams", Academy of Management Journal, Vol. 63 No. 1, pp. 272-294.

Scott, J. and Carrington, P.C. (2011), Handbook of Social Network Analysis, Sage, London.

Shin, J., Taylor, M.S. and Seo, M.-G. (2012), "Resources for change: the relationships of organizational inducements and psychological resilience to employees' attitudes and behaviors toward organizational change", Academy of Management Journal, Vol. 55, pp. 727-748.

Snow, C.C., Fjeldstad, Ø.D. and Langer, A.M. (2017), "Designing the digital organization”, Journal of Organ Dysfunction, Vol. 6 No. 7, pp. 1-13.

Soda, G. and Zaheer, A. (2012), "A network perspective on organizational architecture: performance effects of the interplay of formal and informal organization", Strategic Management Journal, Vol. 33 No. 6, pp. 751-771.

Sosna, M., Trevinyo-Rodríguez, R.N. and Velamuri, S.R. (2010), "Business model innovation through trial-and-error learning: the naturhouse case", Long Range Planning, Vol. 43 Nos 2/3, pp. 383-407.

Teece, D.J. (2010), “Business models, business strategy and innovation”, Long Range Planning, Vol. 43 Nos 2/3, pp. 172-194.

Teece, D.J. (2018), "Business models and dynamic capabilities", Long Range Planning, Vol. 51, pp. 40-49.

Tellis, G.J., Prabhu, J.C. and Chandy, R.K. (2009), "Radical innovation across nations: the preeminence of corporate culture", Journal of Marketing, Vol. 73 No. 1, pp. 3-23.

Zheng, W., Yang, B. and McLean, G. (2010), "Linking organizational culture, structure, strategy, and organizational effectiveness: mediating role of knowledge management", Journal of Business Research, Vol. 63, pp. 763-771.

Zott, C. and Amit, R. (2010), "Business model design: an activity system perspective", Long Range Planning, Vol. 43 No. 2, pp. 216-226.

Zott, C., Amit, C. and Massa, L. (2011), "The business model: recent developments and future research", Journal of Management, Vol. 37 No. 4, pp. 1019-1042.

\section{Corresponding author}

Paolo Di Toma can be contacted at: paolo.ditoma@unimore.it 


\section{Appendix}

This Appendix illustrates the online questionnaires that has been used to collect individual-level information (Section 1 - Personal information) and network data (Section 2-Mapping advice network) about the cooperative's managers.

The matrix presented in Section 2 is an anonymized and reduced version of the one used in the online questionnaire. The original matrix included a roster list with the names of all 136 managers. Multiple choices were allowed: if $a l p h a$ both provided and received advice for creating a new component of the business model ("Creation") to/from beta, she/he was allowed to thick the boxes $\boldsymbol{\square}$ (Out) and (In) in the corresponding columns related to ("Creation").
Overcoming hierarchy in business model innovation

Section 1 - Personal information

1. First name and family name

2. Age

3 . Role in the organization

4. Educational level

5 . How long have you worked for this cooperative? (in years)

6. Are you actually working on projects for developing innovative products or activities other than business model innovation?

$\bar{\neg}$ Yes

(Formal task: e.g. involvement in a working group for testing a new medical procedure)

7. Have you ever worked for organizations providing social services?

$\square$ Yes

8. Have you ever worked for organizations operating in sectors other $\square$ Yes than social service provision?

Section 2 - Mapping advice network

This matrix includes all the managers working in the cooperative. For each manager, we ask you to thick the box(es) $\square$ if, in the last year, you have given (Out) and/or received (In) advice for

- conceptualizing one or more components of the business model or their interaction, even if no changes occurred ("Conceptualization")

- creating a new component of the business model, or a new essential part of this component, based on an analysis of available and needed resources ("Creation")

- adapting the components of the business model or their interaction, according to the experiences gathered during the business model functioning ("Adaptation")

- planning and designing controlled situations for developing new knowledge ("Experimentation”)

\begin{tabular}{lcccccccc}
\hline & \multicolumn{2}{c}{ Conceptualization } & \multicolumn{2}{c}{ Creation } & \multicolumn{2}{c}{ Adaptation } & \multicolumn{2}{c}{ Experimentation } \\
Manager & Out & In & Out & In & Out & In & Out & In \\
\hline Alpha & $\square$ & $\square$ & $\square$ & $\square$ & $\square$ & $\square$ & $\square$ & $\square$ \\
Beta & $\square$ & $\square$ & $\square$ & $\square$ & $\square$ & $\square$ & $\square$ & $\square$ \\
Gamma & $\square$ & $\square$ & $\square$ & $\square$ & $\square$ & $\square$ & $\square$ & $\square$ \\
$\ldots . .$. & $\square$ & $\square$ & $\square$ & $\square$ & $\square$ & $\square$ & $\square$ & $\square$ \\
$\ldots \ldots$. & $\square$ & $\square$ & $\square$ & $\square$ & $\square$ & $\square$ & $\square$ & $\square$ \\
$\ldots \ldots$. & $\square$ & $\square$ & $\square$ & $\square$ & $\square$ & $\square$ & $\square$ & $\square$ \\
$\ldots . .$. & $\square$ & $\square$ & $\square$ & $\square$ & $\square$ & $\square$ & $\square$ & $\square$ \\
Omega & $\square$ & $\square$ & $\square$ & $\square$ & $\square$ & $\square$ & $\square$ & $\square$ \\
\hline
\end{tabular}

